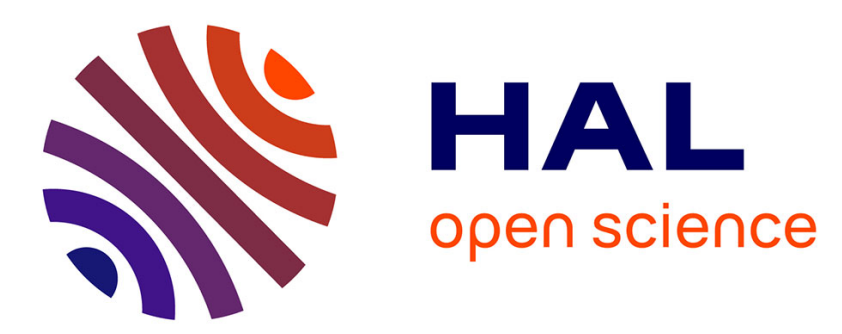

\title{
Hafnium and silicon carbide multilayer coatings for the protection of carbon composites
}

Claire Verdon, Olivier Szwedek, Sylvain Jacques, Alexandre Allemand, Yann Le Petitcorps

\section{> To cite this version:}

Claire Verdon, Olivier Szwedek, Sylvain Jacques, Alexandre Allemand, Yann Le Petitcorps. Hafnium and silicon carbide multilayer coatings for the protection of carbon composites. Surface and Coatings Technology, 2013, 230, pp.124 - 129. 10.1016/j.surfcoat.2013.06.022 . hal-01618197

\section{HAL Id: hal-01618197 https://hal.science/hal-01618197}

Submitted on 17 Oct 2017

HAL is a multi-disciplinary open access archive for the deposit and dissemination of scientific research documents, whether they are published or not. The documents may come from teaching and research institutions in France or abroad, or from public or private research centers.
L'archive ouverte pluridisciplinaire HAL, est destinée au dépôt et à la diffusion de documents scientifiques de niveau recherche, publiés ou non, émanant des établissements d'enseignement et de recherche français ou étrangers, des laboratoires publics ou privés. 


\title{
Hafnium and silicon carbide multilayer coatings for the protection of carbon composites
}

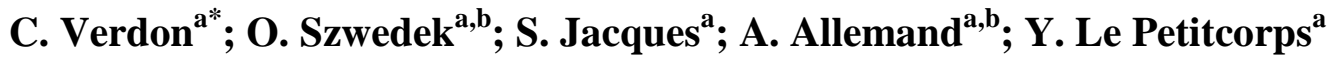 \\ ${ }^{\mathrm{a} U n i v e r s i t y ~ o f ~ B o r d e a u x, ~ C N R S, ~ L C T S, ~ U M R 5801, ~ P e s s a c, ~ F r a n c e ~}$ \\ ${ }^{\mathrm{b}} \mathrm{CEA}, \mathrm{DAM}, \mathrm{LR}, \mathrm{DMAT}$, Monts, France
}

\begin{abstract}
A solution to protect the surface of a carbon/carbon composite from oxidation at high temperature is to combine refractory carbides, such as hafnium and silicon carbides (HfC and $\mathrm{SiC})$. Their depositions have been studied on flat substrates and present major protection against oxidation at high temperature (several minutes at $2000^{\circ} \mathrm{C}$ under air). Infiltration of these carbides layers has been observed inside the open porosities of the carbon substrate which enhance the adhesion of the protection.

The low pressure chemical vapor deposition (LPCVD) process developed here allows multilayer $\mathrm{HfC} / \mathrm{SiC}$ depositions. The $\mathrm{HfC}$ coatings studied have various morphologies and thicknesses depending on the experimental conditions (temperature, pressure, dilution). This carbide has been firstly deposited over flat graphite substrates and carbon single fibers. Secondly, the multilayer coating deposition over a $\mathrm{C} / \mathrm{C}$ composite and over carbon single fibers is studied. Finally, HfC layers have been infiltrated inside carbon fiber tows. To avoid the notch effect on the carbon fibers, a thin layer of pyrocarbon (50 nm thick) has been deposited prior to the growth of the carbides. All the coatings were done in a hot wall CVD reactor and their morphologies and chemical compositions characterized by scanning electron microscopy.
\end{abstract}

Keywords: refractory; carbides; Ultra High Temperature Ceramics; CVD 


\section{INTRODUCTION}

Composites can combine lightness and high thermo-mechanical properties to be used as structural components. $\mathrm{C} / \mathrm{C}$ composites (carbon fibers embedded into a carbon matrix) are especially well-suited since they keep high toughness, shear and stress strength at very high temperatures. However, these composites have a major drawback, they exhibit a poor lifetime under an oxidizing atmosphere; carbon starts to be oxidized under air since $400^{\circ} \mathrm{C}$ [1]. In order to protect these composites from oxidation, many coatings made of Ultra High Temperature Ceramics (UHTCs) have been tested $[2,3]$ such as $\mathrm{TiB}_{2}, \mathrm{ZrB}_{2} \ldots$ They can be synthesis by many ways: CVD with halogeneous [4] or metal-organic precursors [5], or reactive melt infiltration [6] for example.

In a previous work, two refractory carbides have been selected and deposited on flat substrates, SiC and $\mathrm{HfC}$ that develop a synergetic effect against oxidation [7]. A multilayer $\mathrm{HfC} / \mathrm{SiC}$ coating that allows a good oxidation resistance has been obtained [7-9]. The coatings consist of five or ten alternated layers of $\mathrm{SiC}$ and HfC with a total thickness of 20 or $40 \mu \mathrm{m}$. The aim of this study is to investigate the infiltration of this multilayer coating in a $\mathrm{C} / \mathrm{C}$ composite. The SiC deposition and infiltration are well known and industrially applied. However, the difficulty of the $\mathrm{HfC} / \mathrm{SiC}$ multilayer coating deposition is due to $\mathrm{HfC}$ layer itself. Consequently, this study was focused on the HfC deposition and in particular on infiltration parameters (such as temperature, duration) and their influences on the morphology and thickness of the coatings.

First of all in this paper, the low pressure chemical vapor deposition (LPCVD) equipment is described. Secondly, the growth rate of $\mathrm{HfC}$ and the microstructure variation versus temperature is exposed on flat graphite substrates and carbon single fibers. Then, the first results of multilayer deposition on flat graphite substrates and carbon single fibers are presented. Finally, the multilayer coating infiltration results within more and more porous substrates, $\mathrm{PyC} / \mathrm{HfC} / \mathrm{SiC}$ in $\mathrm{C} / \mathrm{C}$ composites with some large open pores and then $\mathrm{PyC} / \mathrm{HfC}$ inside carbon fiber tows, are exposed. The pyrocarbon (PyC) layer was deposited prior to the 
multilayer coating on the carbon single fibers in order to disconnect the carbon fiber from the brittle carbides. It reduces the notch effect which can occur between a carbon fiber and brittle carbides.

\section{EXPERIMENTAL PROCEDURE}

\subsection{Deposition equipment}

The multilayer coatings were prepared by LPCVD by using three interconnected devices (Fig. 1).

The first one was a chlorination device in which $\mathrm{HCl}_{(\mathrm{g})}$ reacts with metallic $\mathrm{Hf}_{(\mathrm{s})}$ at $700^{\circ} \mathrm{C}$ to form $\mathrm{HfCl}_{4(\mathrm{~g})}$, the main gaseous precursors of $\mathrm{Hf}$. The $\mathrm{HfC}$ precursors were $\mathrm{CH}_{4(\mathrm{~g})}, \mathrm{HfCl}_{4(\mathrm{~g})}$ and $\mathrm{H}_{2(\mathrm{~g})} . \mathrm{HfCl}_{4(\mathrm{~g})}$ precursor was injected with argon as a carrier gas (flow rate of $350 \mathrm{sccm}$ ) into the second device through a pipe heated at $500^{\circ} \mathrm{C}$ in order to avoid its condensation. Throughout the study the $\mathrm{H}_{2} / \mathrm{HfCl}_{4}$ ratio was 7.5 with flow rates of $750 \mathrm{sccm}$ for $\mathrm{H}_{2(\mathrm{~g})}$ and 100 sccm for $\mathrm{HfCl}_{4(\mathrm{~g})}$.

This second device was the hot-wall CVD reactor itself which contained the substrates and where both carbide layers, $\mathrm{HfC}$ and $\mathrm{SiC}$, and $\mathrm{PyC}$ were deposited at a temperature ranging from 900 to $1100^{\circ} \mathrm{C}$. The $\mathrm{SiC}$ layers were classically deposited from methyltrichlorosilane (MTS) and hydrogen with a $\mathrm{H}_{2} / \mathrm{MTS}$ ratio of 4 . The third device was an oven containing the MTS and allowing its evaporation and its dilution in hydrogen. PyC layers were deposited

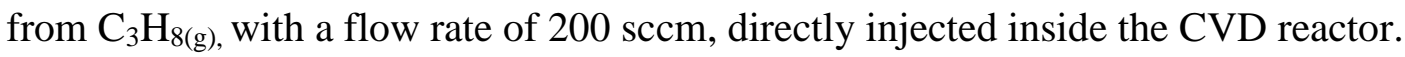

Throughout the study, $\mathrm{HfC}$ and $\mathrm{SiC}$ layers were deposited at $5 \mathrm{kPa}$, and the PyC layers at $2 \mathrm{kPa}$ on carbon single fibers or in fiber tows, whereas a total pressure of $15 \mathrm{kPa}$ was used for the carbide deposition on flat graphite substrates or $\mathrm{C} / \mathrm{C}$ composites.

\subsection{Substrates and reagents.}

The $\mathrm{C} / \mathrm{C}$ composites (density > 1.90) were proprietary materials. Fiber substrates were either T300 single fibers (diameter of $7 \mu \mathrm{m}$ ) or dry 3k T300 carbon fibers tows (Toray, Japan), i.e. 
matrix-free multifiber tows (for infiltration runs), both types being pretreated under vacuum at $800^{\circ} \mathrm{C}$ to thermally remove the sizing. The hafnium metal was an electrolytic grade $\mathrm{Hf}_{(\mathrm{s})}$ supplied by Areva. The MTS was supplied by Sigma Aldrich and its purity was superior to $97 \%$.

\section{3. kinetic study and morphology}

The HfC deposition kinetics was studied first by measuring the thickness of HfC layers deposited on the flat graphite substrates for 2 hours at a temperature ranging from 950 to $1050^{\circ} \mathrm{C}$ and then on carbon single fibers at $1020^{\circ} \mathrm{C}$ for durations ranging from 25 to 60 minutes. In the last case, the studied coatings consisted of a stack of two dual-layers PyC/HfC referred to as $(\mathrm{PyC} / \mathrm{HfC})_{2}$, i.e. a $\mathrm{PyC} / \mathrm{HfC} / \mathrm{PyC} / \mathrm{HfC}$ multilayer sequence. The first PyC layer was used as a mechanical fuse in order to prevent the weakening of the fibers due to the thermal expansion mismatch and to reduce the notch effect which can occur between a carbon fiber and brittle carbides. The second PyC layer was used to distinguish the first layer of HfC to the second one deposited during the same experiment.

For the morphology study, the $(\mathrm{PyC} / \mathrm{HfC})_{2}$ multilayer coatings were deposited at temperatures ranging from 900 to $1100^{\circ} \mathrm{C}$ and compared. The second part of the HfC kinetic deposition study has been realized on fibers within the scope of further coating infiltration. This study has been done at a lower pressure $(5 \mathrm{kPa}$ instead of $15 \mathrm{kPa}$ ) because a lower pressure improves coating infiltration in porous media $[10,11]$. The $(\mathrm{PyC} / \mathrm{HfC})_{2}$ multilayer coatings were also infiltrated inside carbon fiber tows at $950^{\circ} \mathrm{C}$ and $1100^{\circ} \mathrm{C}$.

\subsection{Characterizations}

The coating morphologies were observed by scanning electron microscopy (SEM, Hitachi S4500 FEG) with a secondary electron (SE) detector and an accelerating voltage fixed at $10 \mathrm{kV}$. A second SEM microscope (Quanta 400 FEG V2 microscope) with an accelerating voltage fixed at $5 \mathrm{kV}$ was also used for the coating observations and layer thickness 
measurements. This last SEM is equipped with a Back Scattering Electrons detector (BSE) which completes the secondary electron analysis.

The crystal structure of the sample surface was studied by X-ray diffraction (XRD) with a Diffractometer D8 advance Bruker $(\mathrm{CuK} \alpha)$.

\section{RESULTS AND DISCUSSIONS}

\subsection{HfC deposition by LPCVD on flat graphite substrates and carbon single fibers.}

Fig. 2 shows the thickness variation versus temperature of HfC coatings deposited on flat substrates. This graph reveals that HfC coating deposition is highly thermally activated.

Fig. 3 presents the HfC layer thicknesses obtained from six (PyC/HfC $)_{2}$ multilayer coatings deposited at $1020^{\circ} \mathrm{C}$ with different $\mathrm{HfC}$ layer deposition times.

As a general rule, the thickness of the coating increases almost linearly with the deposition time. But low deposition time reveals the occurrence of an initiation stage of more than 15 minutes that can be assigned to the latency period between starting $\mathrm{HCl}$ gas in the chlorination device and the actual steady-state $\mathrm{HfCl}_{4(\mathrm{~g})}$ production and so the beginning of HfC deposition in the CVD reactor. The phenomenon is emphasized by the important volume formed by the chlorinating facility and gas lines. Furthermore, the first $(\mathrm{C} 1)$ and second $(\mathrm{C} 2)$ HfC layer thicknesses of the multilayer coatings can be quite different for a same deposition time. For example on Fig. 3 for two 35-minute HfC depositions, the second HfC layer is more than twice thicker than the first one, i.e. $520 \mathrm{~nm}$ and $200 \mathrm{~nm}$ thick respectively. However, considering both sets of points, the slopes are similar for $\mathrm{C} 1$ and $\mathrm{C} 2$, respectively 21 and $23 \mathrm{~nm} \cdot \mathrm{min}^{-1}$. Consequently, the deposition kinetics is similar for both layers. The effective deposition starting times for first and second layers are merely shifted by four minutes. Compared with the first HfC layer deposition, the hafnium chlorination steady-state conditions are reached sooner for the second HfC layer when the chlorination is restarted after it has been stopped only a few minutes ago at the end of the first HfC layer deposition. 
For a given deposition time, the thickness of the coating increases overall with temperature showing that the deposition is also thermally activated on the carbon fiber surface (Fig. 4).

In addition to an important transient stage, the uncertainty in the thicknesses of the deposited HfC layers is significant, about $150 \mathrm{~nm}$, and makes further kinetics analyses difficult. Consequently, longer HfC layer depositions will be carried out in the future, especially for the low-temperature range, to obtain thicker layers in well established steady-state conditions and thus to carry out a comprehensive kinetic study.

To deposit HfC-containing matrices in fibrous preforms and to obtain performance composites, it is not only necessary to know the deposition kinetics but also to control the coating morphology which can influence its properties.

\subsection{Morphologies}

\subsubsection{Coatings on flat graphite substrates}

Fig. 5 shows the microstructures of $\mathrm{HfC}$ deposited on flat graphite substrates at $1050^{\circ} \mathrm{C}$ and $1000^{\circ} \mathrm{C}$ and at $15 \mathrm{kPa}$. The coating deposited at $1050^{\circ} \mathrm{C}$ for 2 hours (Fig. 5a) is highly crystallized with large grains (around $3 \mu \mathrm{m}$ in diameter) whereas $\mathrm{HfC}$ deposited at $1000^{\circ} \mathrm{C}$ (Fig. 5b) exhibits sub-micrometer in grain size.

The HfC microstructure is strongly dependent on the deposition temperature. A drop of $50^{\circ} \mathrm{C}$ changed the morphology from a rough to a smooth surface.

\subsubsection{Coatings on carbon single fibers}

Fig. 6 shows significant differences in morphologies of coatings deposited on fiber substrates depending on deposition temperature. At $900^{\circ} \mathrm{C}$ (Fig. 6a) the $\mathrm{HfC}$ coating exhibits a fine granular morphology with an equiaxed structure. At $1020^{\circ} \mathrm{C}$ (Fig. 6b), the coating has a needle-like morphology whereas at $1050^{\circ} \mathrm{C}$ (Fig. 6c), the needle shape crystals are a little less sharp. Finally at higher temperature, $1100^{\circ} \mathrm{C}$ (Fig. 6d), the coating is made of columnar and more coarse grains perpendicular to the substrate surface. XRD analysis of the sample 
surface, exposed on the Fig. 7, gives a pattern typical of crystallized HfC corresponding to the JCPDS 04-0002-5606.

The morphologies of the coatings deposited on carbon fibers are different from those deposited on flat substrates; it could be explained by a reduction of the pressure in the reactor: $5 \mathrm{kPa}$ versus $15 \mathrm{kPa}$.

The morphology and the thickness have to be chosen considering the final application. The roughness is mainly controlled by the temperature, whereas the thickness can be adjusted by the temperature and the duration. Coating morphology, porosity and crystallization rate have an important impact on coating ablation resistance [12]. Y. L. Wang [12] explains that a highly crystallized coating would not be able to release internal stress and accommodate the volume expansion during ablation. He would prefer a particle stacked coating at a highly crystallized coating. However to limit oxygen diffusion in oxidizing atmosphere, an intermediary structure is selected. Based on these results, the coating temperature of $1050^{\circ} \mathrm{C}$ seems to be a good compromise to deposit a coating with suitable morphology, i.e. not too crystallized but enough to avoid porosity. From these results, the HfC deposition has been studied on porous $\mathrm{C} / \mathrm{C}$ composite as well as on fiber tows.

These experiments have been carried out in order to evaluate the HfC infiltration feasibility in fibrous carbon substrate; results are presented in paragraph 3.4.

\subsection{CVD of $\mathrm{HfC} / \mathrm{SiC}$ multilayer coatings}

\subsubsection{Coatings on single carbon fiber}

Fig. 8 shows a multilayer coating over a single carbon fiber at $1020^{\circ} \mathrm{C}$. The coating is made of a $\mathrm{PyC} / \mathrm{SiC} / \mathrm{HfC} / \mathrm{SiC} / \mathrm{PyC} / \mathrm{HfC} / \mathrm{SiC}$ sequence. Each layer of $\mathrm{HfC}$ and $\mathrm{SiC}$ is easily distinguishable whereas PyC layers are not observable because they are thinner $(50 \mathrm{~nm})$ compared to other layers (more than $1 \mu \mathrm{m}$ for SiC layer and for the second HfC layer). The last $\mathrm{HfC} / \mathrm{SiC}$ interface appears serrated, due to the $\mathrm{HfC}$ layer needle-like morphology. 


\subsubsection{Coatings on $\mathrm{C} / \mathrm{C}$ composites}

Multilayer coating has been firstly successfully obtained on 3D C/C composites [7,8]. Coating has been made at $1000^{\circ} \mathrm{C}$ and at a pressure of $5 \mathrm{kPa}$. Each carbide layer, $\mathrm{SiC}$ and $\mathrm{HfC}$, has been deposited for 2 hours.

Fig. 9 shows the $\mathrm{SiC} /(\mathrm{HfC} / \mathrm{SiC})_{2}$ multilayer coating; the layers are homogenous and partially infiltrated inside the open porosities.

\subsection{PyC/HfC infiltration in carbon fiber tows}

After studying the deposition on dense substrates and in order to evaluate the infiltration feasibility of $\mathrm{HfC}$, a (PyC/HfC $)_{2}$ sequence was done within carbon fiber tows. Because reactive gases reach the inside of the tow with more difficulty than single-fiber surface, the kinetics of infiltration within fiber tows is slower than the deposition kinetics on single fibers. But, for short infiltrations time, inferior to sealing time of tow porosity, the infiltration is efficient and the coatings are thicker at high temperature $\left(1100^{\circ} \mathrm{C}\right)$ inside the tow than at low temperature $\left(950^{\circ} \mathrm{C}\right)$. Fig. 10 shows the $(\mathrm{PyC} / \mathrm{HfC})_{2}$ multilayer coatings infiltrated within fiber tows at $1100^{\circ} \mathrm{C}$ and $950^{\circ} \mathrm{C}$ for 30 and 45 minutes for the $\mathrm{C} 1$ and $\mathrm{C} 2 \mathrm{HfC}$ layers respectively, and 10 minutes for the PyC layers. Fig. 10(a) presents a global view of the section of the tow and Fig. 10(c) corresponds to the same section at a higher magnification. Layers are thicker on the outside of the tow than inside in some areas, the coatings are homogeneous and continuous around each fiber. Fig. 10(b) presents a view of some carbon fibers inside the tow and Fig. 10(d) corresponds to the same section at a higher magnification. The HfC coating is visible as white layers which gives evidence for an $\mathrm{HfC}$ infiltration. The multilayer-like structure clearly appears in Fig. 10 (c). However in Fig. 10(b) and (d), discontinuities appear in the multilayer $(\mathrm{PyC} / \mathrm{HfC})_{2}$ coatings and the multilayer-like structure is not well distinguishable around the carbon fibers likely due to too short deposition times. The homogeneity of the HfC infiltration has to be improved by finding the optimum balance between not too high temperature and pressure and an infiltration time long enough as usually 
recommend for the processing of carbon or ceramic matrix composites by chemical vapor infiltration $[10,11]$.

\section{CONCLUSION}

LPCVD process adapted to the deposition of the multilayer coating made of $\mathrm{HfC}, \mathrm{SiC}$ and PyC has the particularity to be composed of three interconnected devices. The HfC coating is the most difficult step during the multilayer deposition process. The thickness of HfC deposit is subject to large uncertainty because of the transient effect due to the chlorination stage. Nevertheless the thickness of the deposited coating increases with temperature and deposition time, when flat or fibers substrates are used.

The HfC coating has various morphologies depending on deposition temperature. Based on these results, $1050^{\circ} \mathrm{C}$ and $5 \mathrm{kPa}$ are the most favorable conditions to get the suitable morphology but, coating infiltration should be enhanced by a decrease of the temperature or the pressure. The multilayer coatings obtained on flat and single fiber substrates show a combined layer with no visible delamination between $\mathrm{HfC}$ and SiC layers. Finally, it has been shown that the infiltration within carbon fiber tows can be achieved. However, the parameters have to be optimized to get a more homogeneous infiltration in the preform.

\section{Acknowledgement}

This work was supported by the "Alternative Energies and Atomic Energy Commission" (CEA). 


\section{References and Notes}

1 D. W. McKee Oxidation Protection of Carbon Materials. In: Thrower PA, editor. Chemistry and physics of carbon, vol. 23. New York: Marcel Dekker; 1991. p. 173232.

2 A. Paul, DD. Jayaseelan, S . Venugopal, E. Zapata-Solvas, J. Binner, B. Vaidhyanathan, A. Heaton, P. Brown, W. E. Lee; UHTC composites for hypersonic applications. Am Ceram Soc Bull 2012;91(1):22-8. (http://hdl.handle.net/2134/9676)

3 E. V. Clougherty, R. L. Pober, L. Kaufman, Synthesis of Oxidation Resistant Metal Diboride Composites. Trans Metall Soc AIME 1968;242:1077-82.

4 S. Motojima, Y. Kawashima, Chemical vapour growth of $\mathrm{HfC}$ whiskers and their morphology, Journal of Materials Science 31, 1996, 3697-3700.

5 G. Boisselier, F. Maury, F. Schuster, SiC coatings grown by liquid injection chemical vapor deposition using single source metal-organic precursors, Surf. Coat. Tech. 215, $2013,152-160$.

6 Y Wang, X Zhu, L Zhang, L. Cheng, C/C-SiC-ZrC composites fabricated by reactive melt infiltration with Si0.87Zr0.13 alloy, Ceramics International, 2010,

7 A. Allemand, L. Bianchi, Y. Le Petitcorps, O. Szwedek, «process for coating a part with an oxidation protective coating» international patent, 2010-10-25, patent application FR2966455, N WO 2012055865.

8 A. Allemand, O. Szwedek, J. F. Epherre, Y. Le Petitcorps, «Procédé pour revêtir une pièce d'un revêtement de protection contre l'oxydation par une technique de dépôt chimique en phase vapeur, et revêtement et pièce » French patent, 2011-11-25, Patent application $\mathrm{N}^{\circ} 1160815$.

9 O. Szwedek, Amélioration du comportement à l'oxydation à très haute température des composites carbone/carbone par des revêtements alternés SiC/HfC. http://ori-oai.u-bordeaux1.fr/pdf/2010/SZWEDEK_OLIVIER_2010.pdf

10 F. Langlais, Comprehensive Composite Material, 4. 20. Chemical vapor infiltration processing of ceramic matrix composites, A. Kelly and C. Zweben eds., Elsevier (2000), 611-644 http://dx.doi.org/10.1016/B0-08-042993-9/00105-4

11 Y. Zhang, R. Luo, Influence of infiltration pressure on densification rate and microstructure of pyrocarbon during chemical vapor infiltration, New Carbon Materials, 2012, 27(1):42-48

12 Y. L. Wang, X. Xiong, G.D. Li, H. F. Liu, Z.K. Chen, W. Sun, Ablation behavior of HfC protective coatings for carbon/carbon composites in an oxyacetylene combustion flame, Corros. Sci. 65 (2012) 549-555 http://dx.doi.org/10.1016/j.corsci.2012.08.064 


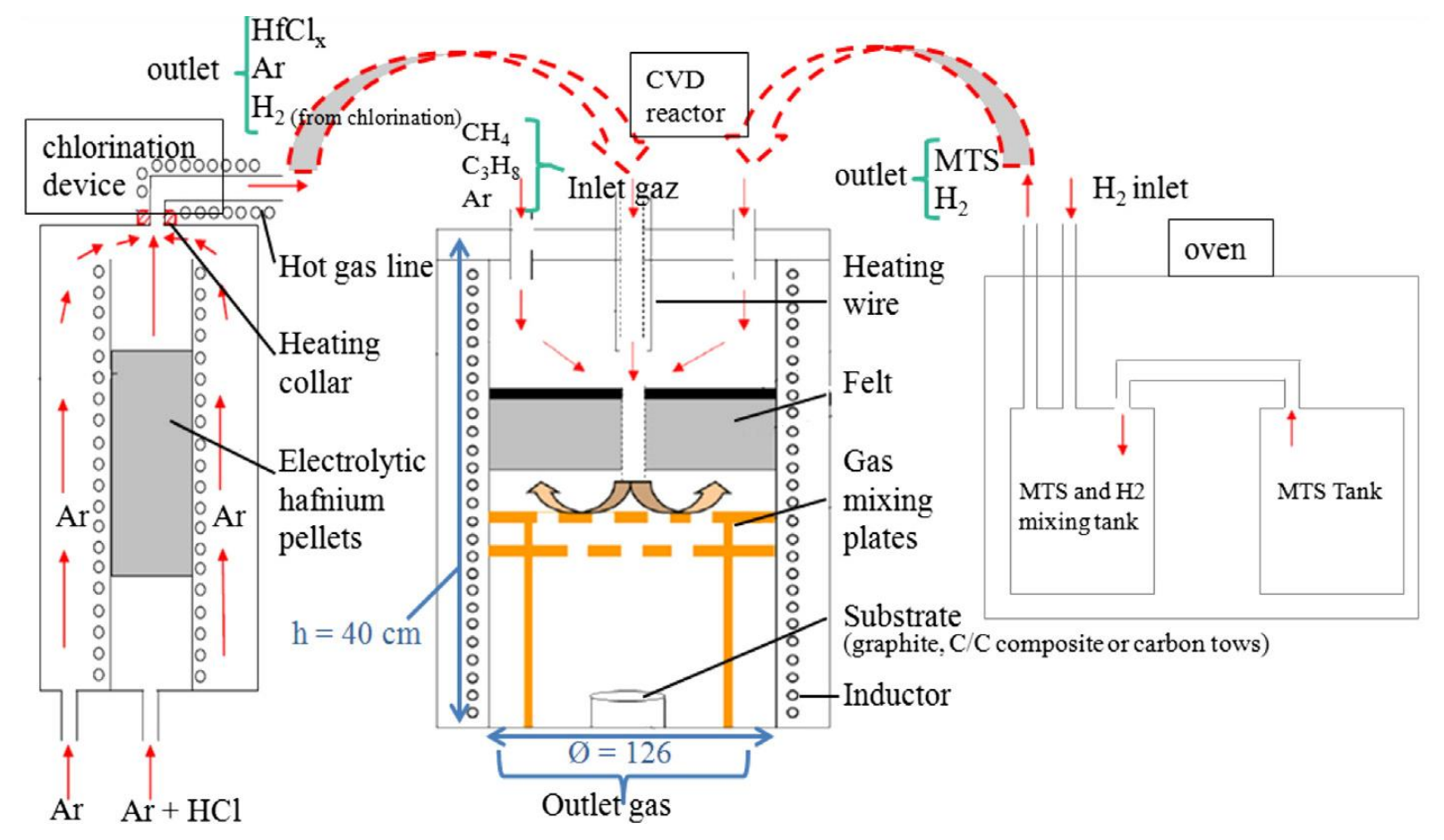

Figure 1: Equipment and involved gas and precursors.

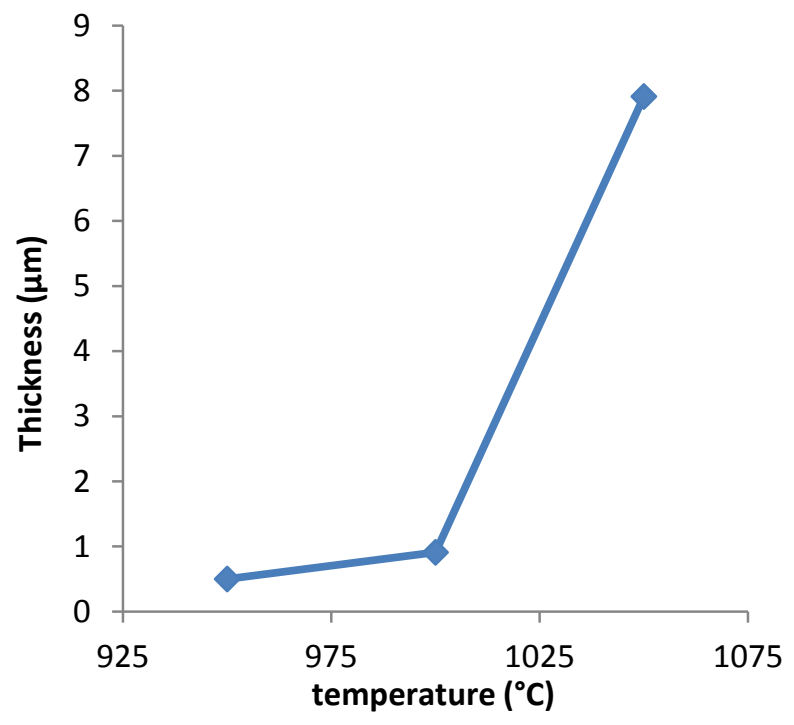

Figure 2: HfC thickness evolution versus temperature, $\mathrm{P}=15 \mathrm{kPa}$, deposition time: $2 \mathrm{~h}$. 

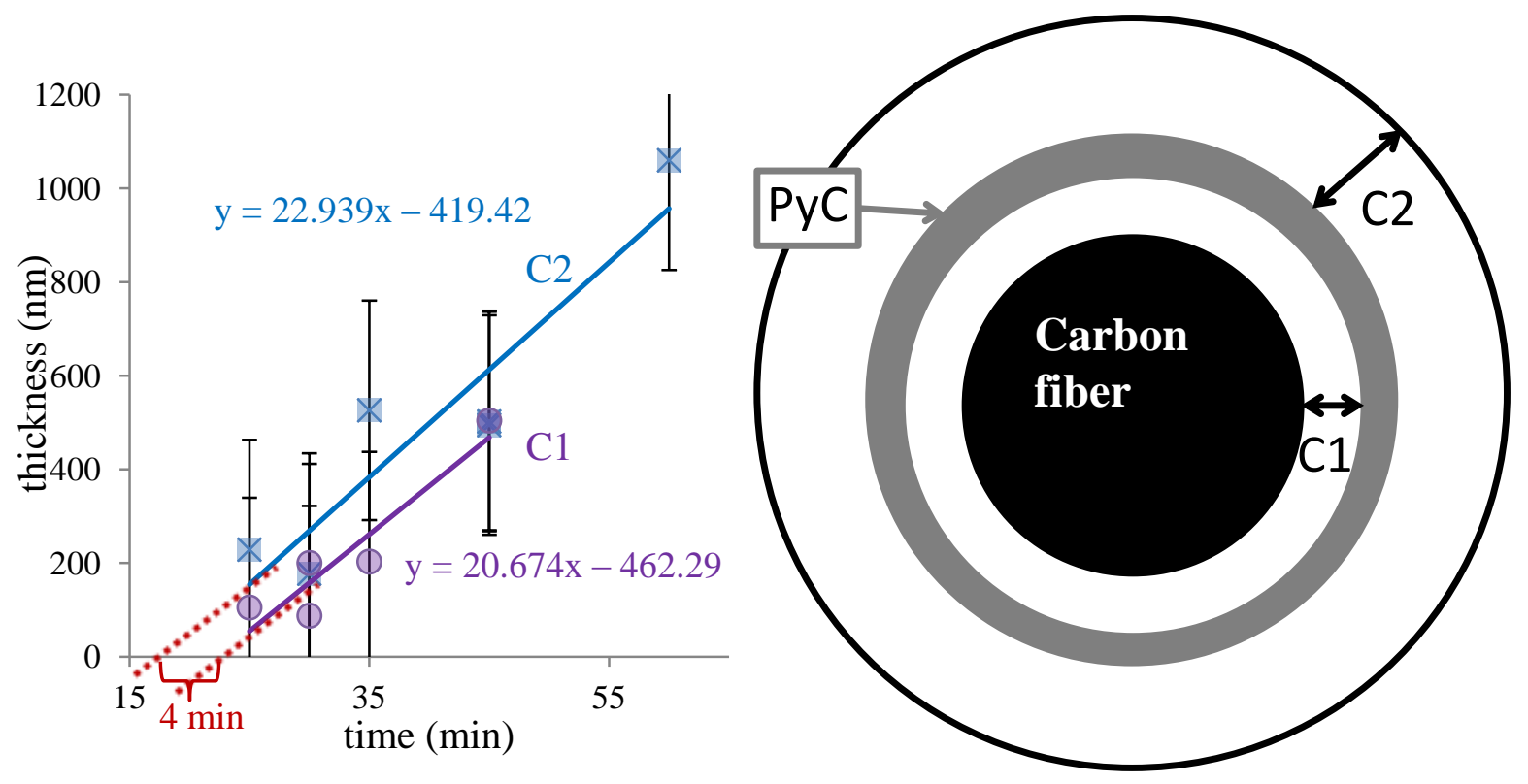

Figure 3: HfC layer thickness versus deposition time at $1020^{\circ} \mathrm{C}$ and schematic drawing cross section showing the first $(\mathrm{C} 1)$ and the second $(\mathrm{C} 2)$ $\mathrm{HfC}$ layer of a $(\mathrm{PyC} / \mathrm{HfC})_{2}$ multilayer coating.

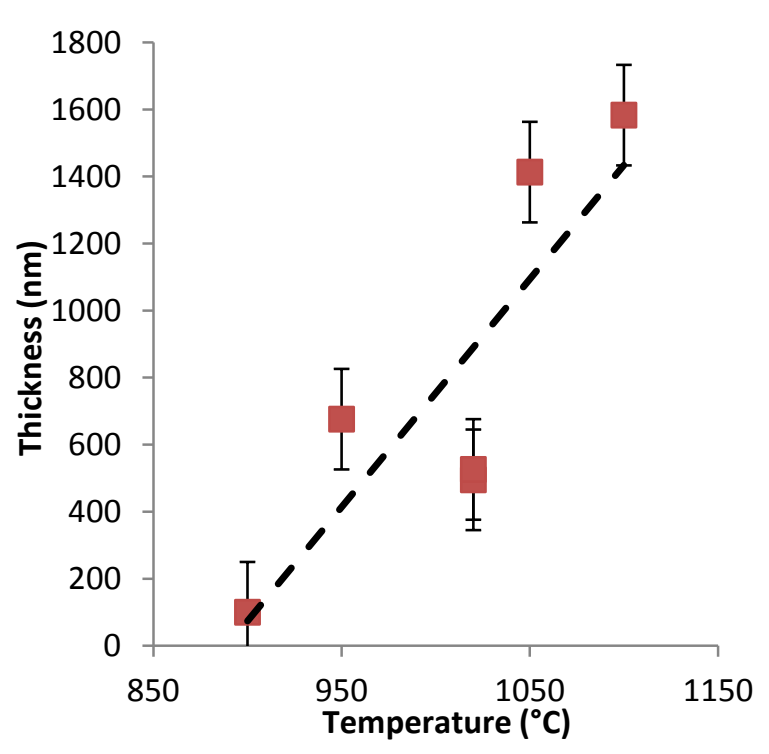

Figure 4: HfC coating thickness evolution versus temperature for $45 \mathrm{~min}$ deposition on carbon single fiber at a total pressure of $5 \mathrm{kPa}$. 

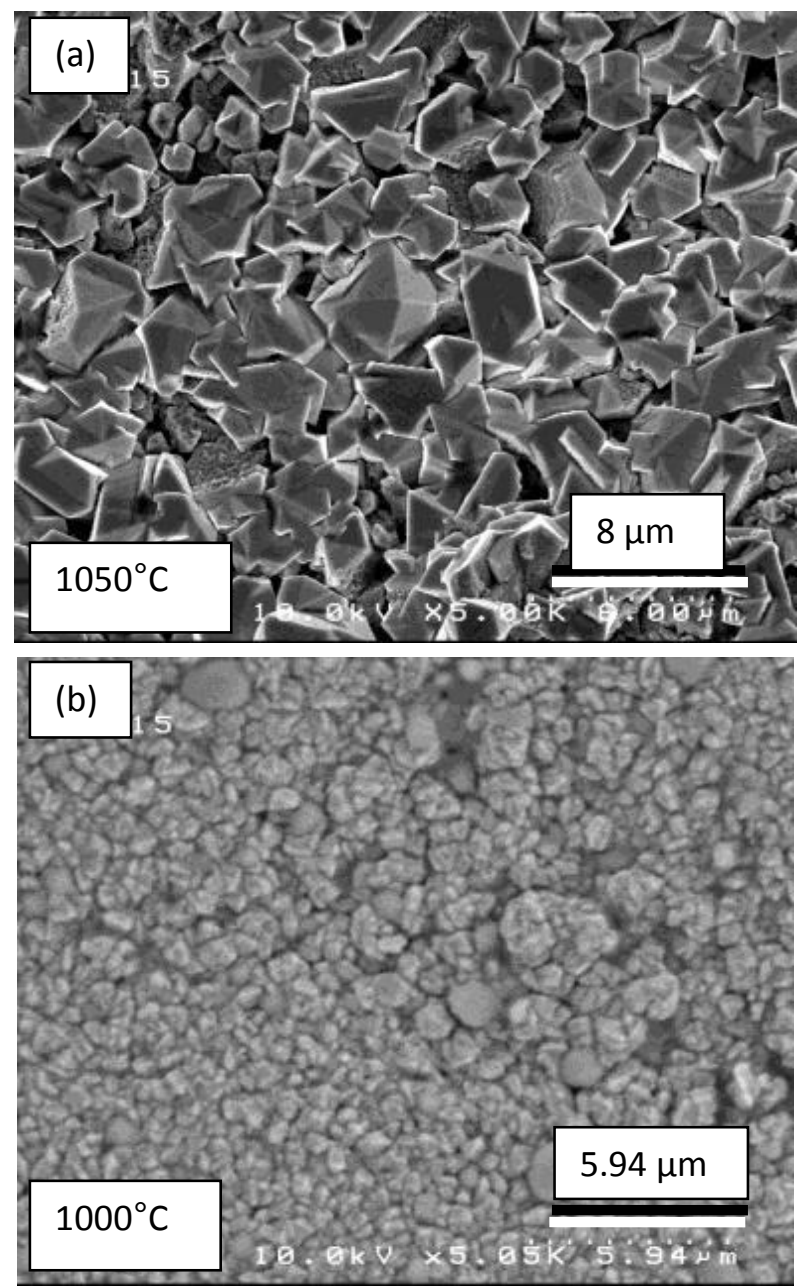

Figure 5: SE SEM observations of the surface of $\mathrm{HfC}$ deposited on graphite flat substrates at $15 \mathrm{kPa}$ for $2 \mathrm{~h}$ at $1050^{\circ} \mathrm{C}$ (a) and $1000^{\circ} \mathrm{C} \mathrm{(b).} \mathrm{Coating}$ thickness is $7.91 \mu \mathrm{m}$ (a) and $0.91 \mu \mathrm{m}(\mathrm{b})$. 

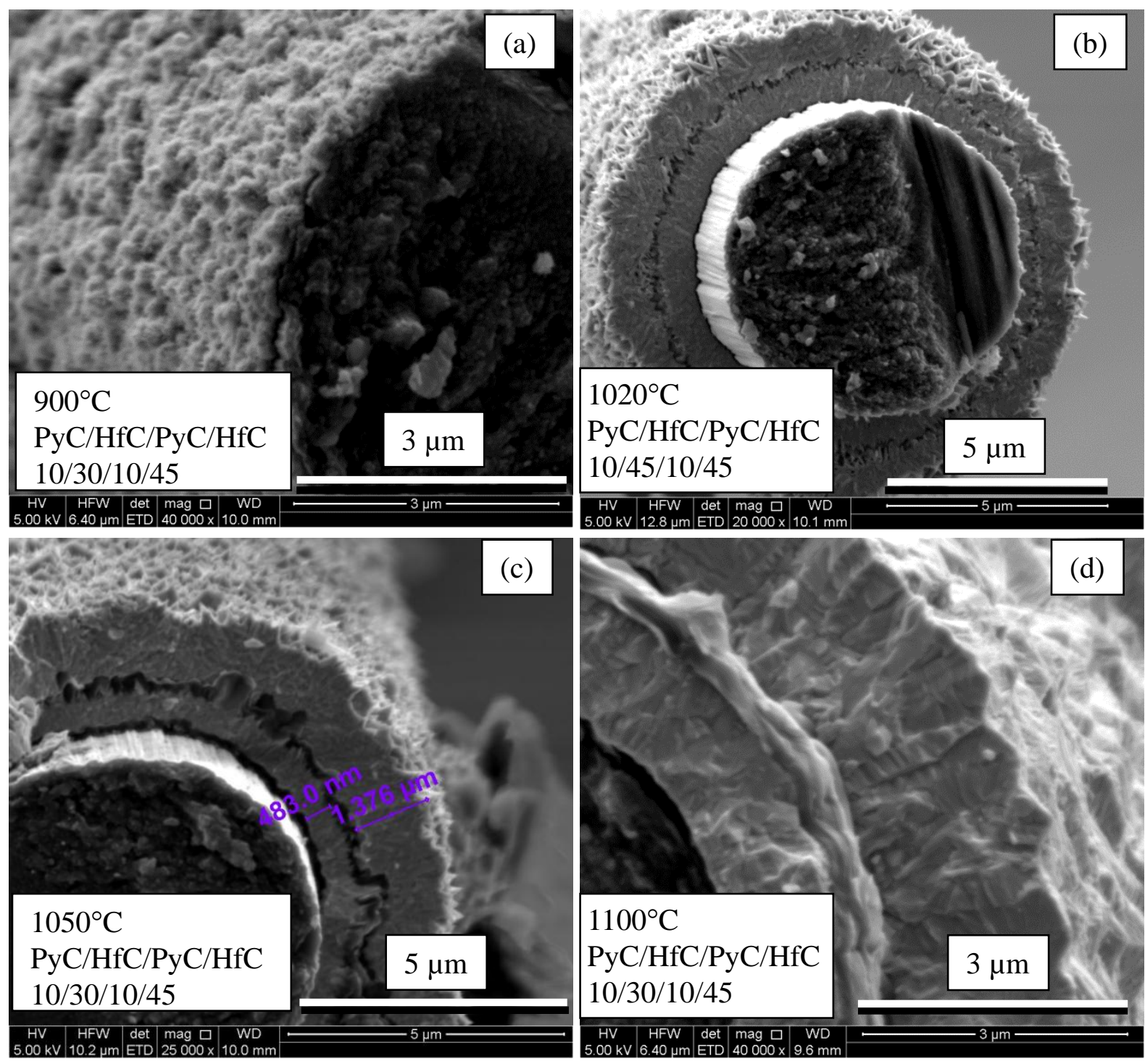

Figure 6: SE SEM observations of fractured (PyC/HfC $)_{2}$ multilayer coatings deposited on carbon fibers at $900^{\circ} \mathrm{C}(\mathrm{a}), 1020^{\circ} \mathrm{C}(\mathrm{b}), 1050^{\circ} \mathrm{C}(\mathrm{c})$ and $1100^{\circ} \mathrm{C}(\mathrm{d})$. The sub-layer deposition times are given in minutes. 


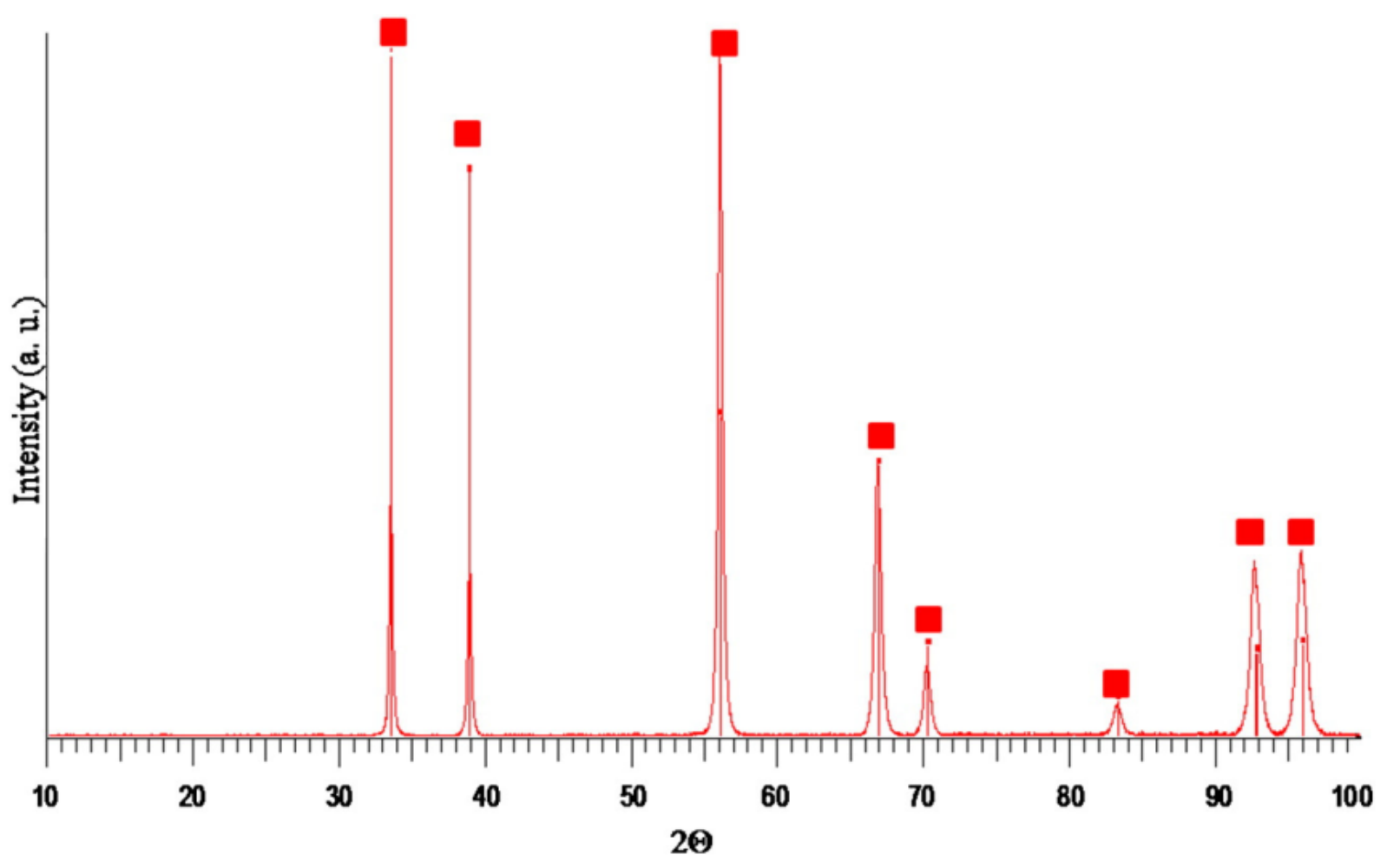

Figure 7: X-ray diffractogram of surface of $\mathrm{HfC}$ coating deposited at $1100^{\circ} \mathrm{C}$ and the corresponding JCPDS 04-0002-5606.

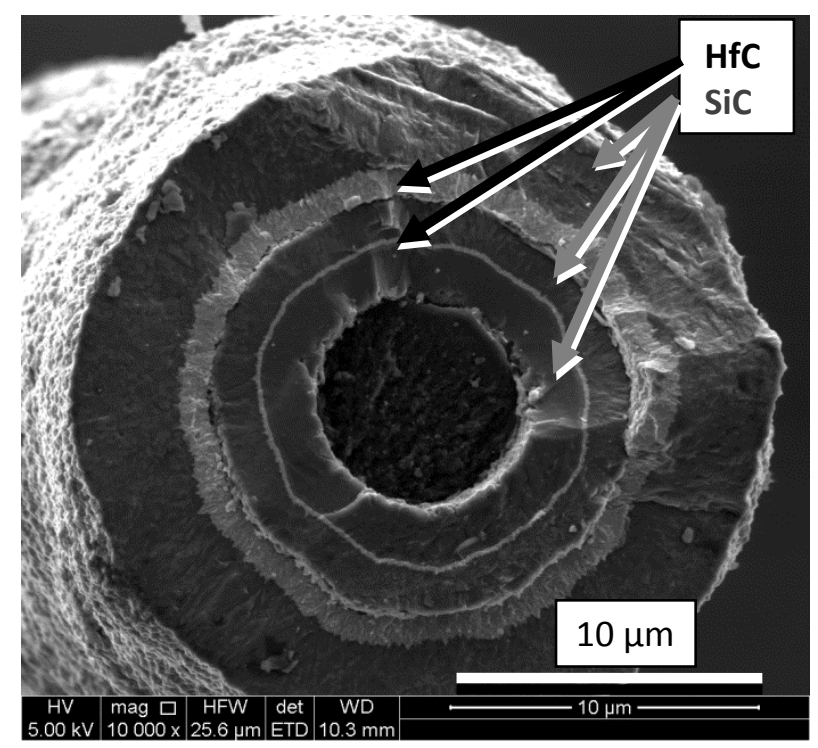

Figure 8: SE SEM observation of a carbon fiber section after deposition of a multilayer coating made of $\mathrm{SiC}, \mathrm{HfC}$ and $\mathrm{PyC}$ and deposition conditions. 


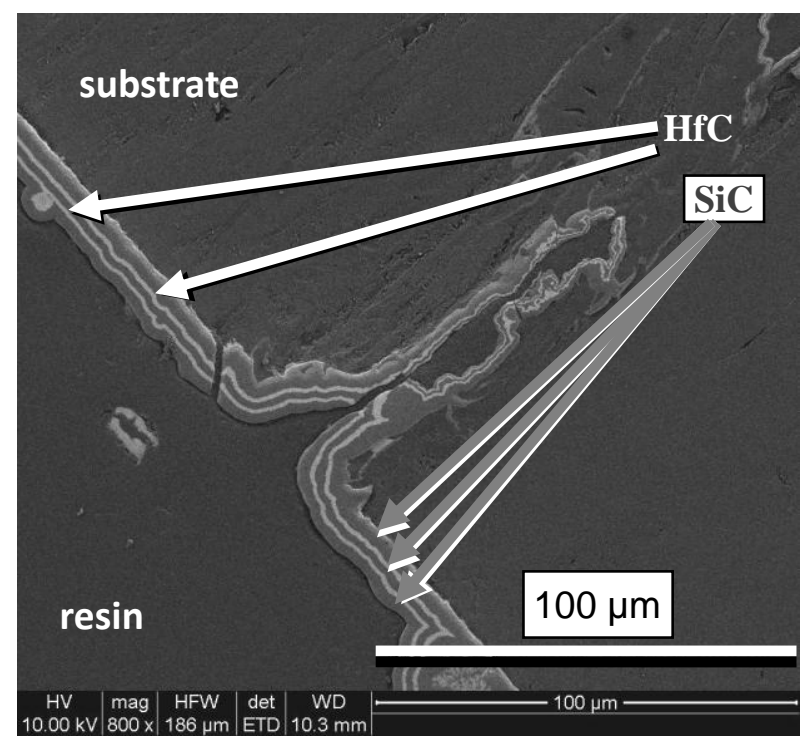

Figure 9: $\mathrm{SE} \mathrm{SEM}$ observation of a $\mathrm{SiC} /(\mathrm{HfC} / \mathrm{SiC})_{2}$ multilayer coatings deposited on a $\mathrm{C} / \mathrm{C}$ composite showing the infiltration in a pore.

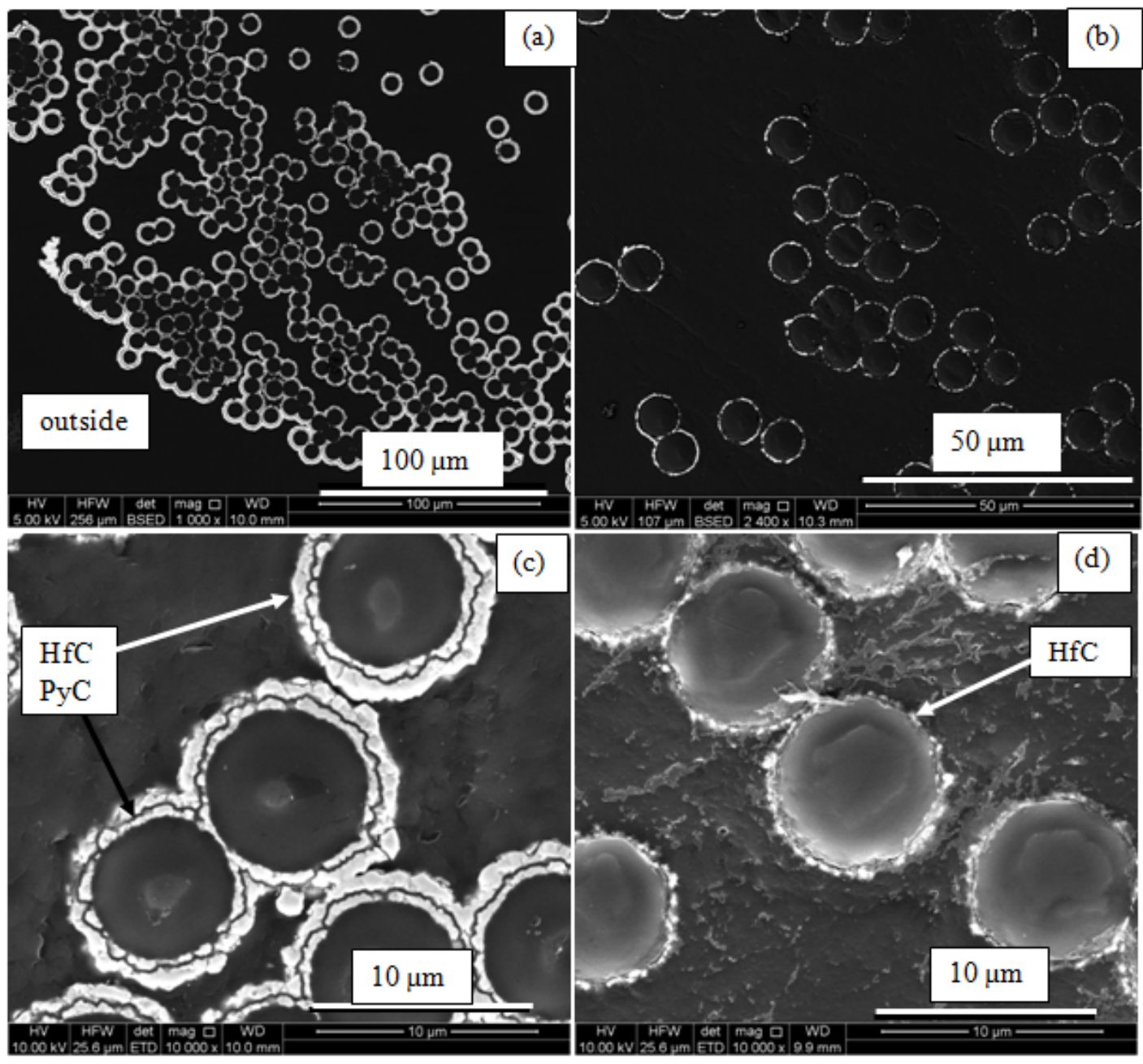

Figure 10: $\mathrm{BSE}$ SEM images of $(\mathrm{PyC} / \mathrm{HfC})_{2}$ multilayers infiltrated within a carbon fiber tow at $1100^{\circ} \mathrm{C}$ (a) \& (c) and $950^{\circ} \mathrm{C}$ (b) \& (d). 